Old Dominion University

ODU Digital Commons

\title{
Biolability of Fresh and Photodegraded Pyrogenic Dissolved Organic Matter From Laboratory-Prepared Chars
}

\author{
K. W. Bostick
}

A. R. Zimmerman

A. I. Goranov

Old Dominion University, agoranov@odu.edu

S. Mitra

P. G. Hatcher

Old Dominion University, phatcher@odu.edu

See next page for additional authors

Follow this and additional works at: https://digitalcommons.odu.edu/chemistry_fac_pubs

Part of the Environmental Chemistry Commons, Organic Chemistry Commons, and the Terrestrial and Aquatic Ecology Commons

\section{Original Publication Citation}

Bostick, K. W., Zimmerman, A. R., Goranov, A. I., Mitra, S., Hatcher, P. G., \& Wozniak, A. S. (2021). Biolability of fresh and photodegraded pyrogenic dissolved organic matter from laboratory-prepared chars. Journal of Geophysical Research: Biogeosciences, 126(5), 1-17, Article e2020JG005981. https://doi.org/10.1029/ 2020JG005981

This Article is brought to you for free and open access by the Chemistry \& Biochemistry at ODU Digital Commons. It has been accepted for inclusion in Chemistry \& Biochemistry Faculty Publications by an authorized administrator of ODU Digital Commons. For more information, please contact digitalcommons@odu.edu. 


\section{Authors}

K. W. Bostick, A. R. Zimmerman, A. I. Goranov, S. Mitra, P. G. Hatcher, and A. S. Wozniak 


\section{JGR Biogeosciences}

\author{
RESEARCH ARTICLE \\ 10.1029/2020JG005981 \\ Key Points: \\ - About half of pyrogenic dissolved \\ organic carbon (pyDOC) was \\ mineralized by soil microbes over \\ 96 days \\ - pyDOC from chars made at lower \\ temperatures and those pre-exposed \\ to sunlight were biomineralized to \\ greater extents \\ - Biomineralization caused relative \\ increases in alkyl- and oxy-C, while \\ aryl- (including condensed $\mathrm{C}$ ) and \\ low molecular weight-C decreased
}

Supporting Information:

Supporting Information may be found in the online version of this article.

Correspondence to:

A. R. Zimmerman,

azimmer@ufl.edu

Citation:

Bostick, K. W., Zimmerman, A. R., Goranov, A. I., Mitra, S., Hatcher, P. G., \& Wozniak, A. S. (2021). Biolability of fresh and photodegraded pyrogenic dissolved organic matter from laboratory-prepared chars. Journal of Geophysical Research: Biogeosciences, 126, e2020JG005981. https://doi. org/10.1029/2020JG005981

Received 21 JUL 2020

Accepted 15 APR 2021

Author Contributions:

Conceptualization: K. W. Bostick, A. R. Zimmerman, S. Mitra, P. G. Hatcher A. S. Wozniak

Formal analysis: K. W. Bostick, A. R. Zimmerman, A. I. Goranov

Investigation: $\mathrm{K}$. W. Bostick, A. R.

Zimmerman

Methodology: A. R. Zimmerman

Project Administration: A. R.

Zimmerman

Supervision: A. R. Zimmerman, P. G. Hatcher

Writing - original draft: $\mathrm{K}$. W. Bostick, A. R. Zimmerman

Writing - review \& editing: A. R. Zimmerman, A. I. Goranov, S. Mitra, P. G. Hatcher, A. S. Wozniak

(C) 2021. American Geophysical Union. All Rights Reserved.

\section{Biolability of Fresh and Photodegraded Pyrogenic Dissolved Organic Matter From Laboratory-Prepared Chars}

\author{
K. W. Bostick ${ }^{1,2}$, A. R. Zimmerman ${ }^{1}$ (1), A. I. Goranov ${ }^{3}$, S. Mitra ${ }^{4}$ (), P. G. Hatcher ${ }^{3}$, and \\ A. S. Wozniak ${ }^{5}$ \\ ${ }^{1}$ Department of Geological Sciences, University of Florida, Gainesville, FL, USA, ${ }^{2}$ Fugro USA Marine Inc., Seep \\ Exploration, Houston, TX, USA, ${ }^{3}$ Department of Chemistry and Biochemistry, Old Dominion University, Norfolk, VA, \\ USA, ${ }^{4}$ Department of Geological Sciences, East Carolina University, Greenville, NC, USA, ${ }^{5}$ School of Marine Science \\ and Policy, College of Earth, Ocean, and Environment, University of Delaware, Lewes, DE, USA
}

Abstract Pyrogenic dissolved organic matter (pyDOM) is known to be an important biogeochemical constituent of aquatic ecosystems and the carbon cycle. While recent studies have examined how pyDOM production, composition, and photolability varies with parent pyrogenic solid material type, we lack an understanding of potential microbial mineralization and transformation of pyDOM in the biogeosphere. Thus, leachates of oak, charred at $400{ }^{\circ} \mathrm{C}$ and $650{ }^{\circ} \mathrm{C}$, as well as their photodegraded counterparts were incubated with a soil-extracted microbial consortium over 96 days. During the incubation, significantly more carbon was biomineralized from the lower versus higher temperature char leachate (45\% vs. $37 \%$ lost, respectively). Further, the photodegraded leachates were biomineralized to significantly greater extents than their fresh non-photodegraded counterparts. Kinetic modeling identified the mineralizable pyDOC fractions to have half-lives of 9-13 days. Proton nuclear magnetic resonance spectroscopy indicated that the majority of this loss could be attributed to low molecular weight constituents of pyDOM (i.e., simple alcohols and acids). Further, the quantification of benzenepolycarboxylic acid (BPCA) molecular markers indicated that condensed aromatic compounds in pyDOM were biomineralized to much lesser extents (4.4\% and $10.1 \%$ decrease in yields of $\Sigma$ BPCA-C over 66 days from $400{ }^{\circ} \mathrm{C}$ and $650{ }^{\circ} \mathrm{C}$ oak pyDOM, respectively), but most of this loss could be attributed to the biomineralization of smaller condensed clusters (four aromatic rings or less). These results highlight the contrasting bioavailability of different portions of pyDOM, and the need to examine both to evaluate its role in soil or aquatic heterotrophy and its environmental fate in the hydrogeosphere.

Plain Language Summary Given the recent changes in wildfire frequency and intensity in many areas of the globe, it is important to understand the fate of charred biomass in soils. As char is degraded in soils, it dissolves into porewaters, from where it then moves through the soil into rivers and ultimately to the ocean. The current study strives to understand how microbial decomposition destroys or alters fire-derived dissolved organic carbon. To accomplish this, two chars were leached in water and were incubated with soil microbes. This study found that about half of the carbon in these leachates could be readily decomposed, that is, converted back to carbon dioxide (with some variation with char leachate type). However, the other half of the leachate was resistant to microbial utilization. As such, one could expect that this remaining portion might be transported by rivers to the ocean, potentially influencing aquatic ecology and global carbon cycling.

\section{Introduction}

Fire-derived or "pyrogenic" carbon (pyC) constitutes $\sim 10 \%$ of soil and sediment organic carbon, on average (Bird et al., 1999; Cusack et al., 2012). While generally considered recalcitrant in the geosphere, pyrogenic organic matter $(\mathrm{OM})$ can undergo dissolution aided by abiotic and biotic oxidation (Abiven et al., 2011; Cheng et al., 2006; Roebuck et al., 2017; Sorrenti et al., 2016), forming pyrogenic dissolved organic matter (pyDOM). Following fires, this pyDOM may be retained within soils (e.g., Ding et al., 2013; Santos et al., 2017; Wagner et al., 2015) or it may leach from soils and enter aquatic carbon pools (Santos et al., 2019). A component of pyDOM, namely condensed aromatic carbon (ConAC), has been identified 
in wetlands (Ding et al., 2014), rivers (Ding et al., 2015), oceans (Stubbins, Niggemann, \& Dittmar, 2012; Ziolkowski \& Druffel, 2010), and even glacial outflows (Stubbins, Hood, et al., 2012), using benzenepolycarboxylic acid (BPCA) molecular markers. Based on field and experimental leaching studies, between 18 and $203 \mathrm{Tg}$ of pyrogenic dissolved organic carbon (pyDOC) may be entering aquatic systems annually (Bostick et al., 2018; Jaffé et al., 2013; Jones et al., 2020).

However, as a whole, this pyDOM is a heterogeneous mixture of low molecular weight compounds (e.g., acetate, methanol, and formate), oxygenated aliphatic hydrocarbons, thermally altered biopolymers, and ConAC (Bostick et al., 2018; Fu et al., 2016; Norwood et al., 2013). The absolute and relative amount of these components varies with the pyDOM type. For example, the amount of pyDOM leached from chars decreases with parent charring temperature and is relatively greater from grass versus oaks parent chars (Bostick et al., 2018; Mukherjee \& Zimmerman, 2013; Wozniak et al., 2020). Further, the proportion of ConAC in leached pyDOM generally increases with charring temperature (Bostick et al., 2018; Fu et al., 2016). Thus, the chemistry of pyDOM is likely to affect its resistance to microbial degradation.

To understand the impacts of pyDOM on global carbon cycling, as well as its potential effects on aquatic heterotrophy, and even environmental and human health, the mobility and fate of pyDOM must be better understood. Several laboratory and field studies show that photochemical degradation is a major pyDOM mineralization and alteration pathway, particularly for its aromatic fraction (Bostick et al., 2020; Myers-Pigg et al., 2015; Stubbins, Niggemann, \& Dittmar, 2012; Wagner et al., 2018; Ward et al., 2014). However, pyDOC is also likely susceptible to biomineralization given that solid chars are biolabile to some degree (Baldock \& Smernik, 2002; S. Bruun et al., 2008; E. W. Bruun et al., 2012; Zimmerman, 2010). In particular, pyDOM is rich in O-containing, aliphatic, and low molecular weight compounds (the more soluble components of char, e.g., Bostick et al., 2018), which are likely to be bioavailable (e.g., Herlihy et al., 1987).

Till date, studies that examined the biolability of pyDOM components have been few and have considered either only the condensed aromatic portion that is generally thought to be quite biorecalcitrant and difficult to metabolize, or the non-condensed portion that has been shown to be readily biomineralizable, but not both. For example, Kim et al. (2006) found that hydrogen-deficient molecules with low H:C ratios (condensed OM) in DOM tropical stream were generally not lost when fed through a biofilm reactor. Only $2 \%$ of condensed aromatic compounds in Arctic permafrost-draining streams were lost during laboratory incubations (Spencer et al., 2015). In a microbial incubation study (Norwood et al., 2013), more than half the pyDOC from mesquite char leachates were mineralized within 1 month. In this same study, levoglucosan derived from thermally altered carbohydrates, and free lignin phenols were almost completely lost in this timeframe. However, it should be kept in mind that these char leachates were made at $250{ }^{\circ} \mathrm{C}$, and, therefore, are relatively poor in ConAC, while most chars are prepared at higher temperatures $\left(>500{ }^{\circ} \mathrm{C}\right)$.

Because BPCAs are commonly used to identify pyDOM in natural samples, and these compounds are derived only from their condensed aromatic OM portions, pyDOM is often represented as biorefractory (Wagner et al., 2018). However, environmental biodegradation of aromatic OM does occur. Using dioxygenase, manganese peroxidase, and monoxygenase enzymes, both lignolytic fungi and a wide variety of bacteria are able to oxidize small-cluster ConAC such as polycyclic aromatic hydrocarbons (PAH) into simple phenolic compounds (Bamforth \& Singleton, 2005; Higuchi, 2004), though the energy yields are low. Suggestion of the role of these processes in pyDOM degradation via microbial activity may also be found in the $20 \%-80 \%$ increases in soil phenol oxidase activity in forest soils following burning events (Boerner \& Brinkman, 2003). These enzymes play a role in the decomposition and transformation of polycyclic aromatic compounds (Sack et al., 1997). However, the breakdown of this aromatic fraction of pyDOM by microbes has not been specifically shown.

The ConAC portion, and to a lesser extent the non-condensed portion of pyDOM, has been shown to be highly photolabile, with $75 \%-94 \%$ of ConAC and $5 \%-8 \%$ of non-ConAC lost over 5 days of photoexposure (Bostick et al., 2020). However, photomineralization may not be able to account for the majority of pyDOM loss in the hydrosphere given that pyDOM spends only a small portion of its lifetime exposed to sunlight. For example, Amon and Benner (1996) calculated that, for Amazon River DOM, while photomineralization rates were seven times greater than those of microbial DOC utilization, when integrated over the entire water column, microbial mineralization accounted for much more of the overall DOC loss. 
It may be that biolability of pyDOM increases by photoexposure. Several studies have shown that light exposure can increase the bioavailability of glacial, wetland, lacustrine, and marine DOM (Antony et al., 2018; Kieber et al., 1989; Lindell et al., 1995; Rossel et al., 2013), possibly due to the cleavage of macromolecules into smaller, more bioavailable units. Other studies found light to have little to no effect of photoexposure on DOM bioavailability (Amon \& Benner, 1996; Andrews et al., 2000; Anesio et al., 2005; Benner \& Biddanda, 1998). Still other studies suggested that photoexposure decreases biolability of DOM (Anesio et al., 1999; Keil \& Kirchman, 1994; Tranvik \& Kokalj, 1998). Given the characteristic photolability of pyDOM, its photoproducts may have unrecognized impacts on pyDOM microbial uptake and subsequent biomineralization.

In order to assess the influence of pyDOM on global $\mathrm{C}$ cycling, aquatic ecosystems, and to predict how these may affect aquatic pyDOM levels to increase, a better understanding of pyDOM biolability is needed. However, because pyDOM made at different temperatures vary widely in composition, particularly in regard to its condensed aromatic content, pyDOM derived from chars of a range of thermal maturities must be examined. Further, there is a need to simultaneously study the biolability of both condensed and non-condensed portions of pyDOM. Lastly, there is a need to understand the effects of photoexposure on pyDOM biolability. Therefore, in the current study, microbial incubations of fresh and photoirradiated leachates derived from chars of different thermal maturities were conducted. While pyDOC measurements were used to track the kinetics of overall biomineralization, BPCA analyses and spectroscopic methods were used to identify the biolability of various pyDOM components. We hypothesize the occurrence of two phases of pyDOM biomineralization where small aliphatic compounds, particularly those with oxygen-containing functional groups are lost quickly, and condensed aromatic components are lost more slowly at rates controlled by the cleavage of aromatic structures (e.g., da Cunha-Santino \& Bianchini, 2002; Kiikkila et al., 2013; Qualls, 2005). Further, given that photoexposure preferentially reduces its condensed aromatic and likely more bio-refractory portion (Bostick et al., 2020; Fu et al., 2016), we hypothesize that photoexposure will increase the biolability of pyDOM. Testing these hypotheses will lead to a better understanding of pyDOM lability in the biogeosphere, as well as the molecular markers that are used to track pyDOM in the environment.

\section{Materials and Methods}

\subsection{Production of Pyrogenic Parent Solids and Their Leachates}

Two chars were produced from laurel oak wood (Quercus hemisphaerica, roughly $0.5 \times 0.5 \times 4 \mathrm{~cm}$ pieces) by pyrolysis under flowing $\mathrm{N}_{2}$ (held at peak temperatures of $400{ }^{\circ} \mathrm{C}$ and $650{ }^{\circ} \mathrm{C}$ for $3 \mathrm{~h}$ ) and designated Oak400 and Oak-650, respectively. Physiochemical data on these chars and their aqueous leachates have been reported previously (Table S1, Bostick et al., 2018; Mukherjee \& Zimmerman, 2013; Zimmerman, 2010).

Mortar, pestle, and sieving were used to isolate a semi-uniform 0.25-2.0 mm char particle size fraction used for leachate production. Using combusted glassware, approximately $5 \mathrm{~g}$ of each solid sample was added to $500 \mathrm{~mL}$ of MilliQ Nanopure water $(18.1 \mathrm{M} \Omega)$ in $1 \mathrm{~L}$ amber-glass bottles. Following Bostick et al. (2018), the bottles were agitated on a platform shaker table at $80 \mathrm{rpm}$ in the dark. After $50 \mathrm{~h}$, the leachates were pre-filtered through Fisherbrand glass fiber filters (1.0 $\mathrm{mm}$ particle retention), and subsequently filtered using a mixed cellulose ester $(0.22 \mu \mathrm{m}$ particle retention; Millipore GSWP) with the aid of a vacuum flask-based filtration manifold.

\subsection{Photodegradation of pyDOM}

A portion of each leachate was photoincubated for 5 days prior to microbial incubation. Aliquots of each leachate $(80 \mathrm{~mL})$ were transferred to $100 \mathrm{~mL}$ tubular quartz reaction vessels $(\sim 50 \mathrm{~cm}$ long, $3 \mathrm{~cm}$ outer diameter, $2 \mathrm{~mm}$ thick walls), sealed with Teflon caps, and placed horizontally in a photoincubation box with a ventilation fan to be held at room temperature $\left(24{ }^{\circ} \mathrm{C}-26{ }^{\circ} \mathrm{C}\right)$. Sunlight was simulated with four 40 watt, UV-A $340 \mathrm{~nm}$ lamps (Q-Lab Corporation) attached $27 \mathrm{~cm}$ from the quartz reaction vessels (Figure S1). These bulbs provided UV radiation approximating natural sunlight in the 295-365 nm wavelength region, which is the principal range for environmental photochemical reactions (Helms et al., 2008; Spencer et al., 2009). The irradiation energy at the water surface was estimated to be approximately 1.2 times of the terrestrial solar irradiation energy (i.e., 5 days in the photoincubation box simulates approximately 12 days 
of irradiation assuming $12 \mathrm{~h}$ light per day, Bostick et al., 2020). Hereafter, photodegraded leachate samples are designated with "Photo" as a prefix (e.g., Photo Oak-400) while non-irradiated samples are prefixed with "Fresh” (e.g., Fresh Oak-650).

\subsection{Microbial Incubations}

Microbial inoculants were extracted from the organic-rich upper $5 \mathrm{~cm}$ horizon of an Ultic Alaquod soil in a pine-dominated (Pinus palustris) upland forest in North-Central Florida $\left(29^{\circ} 45^{\prime} 26.5^{\prime \prime} \mathrm{N}, 82^{\circ} 12^{\prime} 16.2 \mathrm{~W}\right.$, Figure S2). This site was selected because it is frequently subjected to prescribed burns (burnt at least twice per decade, Johns, 2016). As a result, this soil microbial consortia may regularly interact with pyrogenic OM. Genetic sequencing revealed the microbial taxa of this soil to be enriched in Proteobacteria of the classes Gemmatimonadetes and Actinobacteria, suggesting that these communities are predisposed to the utilization of pyrogenic carbon (Khodadad et al., 2011).

After sieving to remove roots and large detritus $(>125 \mu \mathrm{m})$, the soil was homogenized manually. In order to concentrate soil microbes, approximately $5 \mathrm{~g}$ soil subsets were mixed with $50 \mathrm{~mL}$ MilliQ Nanopure water $(18.1 \mathrm{M} \Omega)$ in beakers over a warm plate $\left(30^{\circ} \mathrm{C}\right)$, and gently agitated with magnetic stir bars for $45 \mathrm{~min}$. Following Zimmerman (2010), after filtering with a $1.0 \mu \mathrm{m}$ glass fiber filter (FisherBrand, G2) and centrifugation (400 rpm, $10 \mathrm{~min}$ ), the soil leachate supernatant was decanted. The remaining centrifugate pellets were combined, added to $10 \mathrm{~mL}$ MilliQ Nanopure water, and used as the microbial inoculant.

Aliquots of fresh and photoirradiated Oak-400 and Oak-650 leachates (50 mL) were diluted to a uniform dissolved organic carbon (DOC, see below) concentration of $4.7 \mathrm{mg} \mathrm{C} \mathrm{L}^{-1}$ and placed in $100 \mathrm{~mL}$ amber glass vials and topped with gas-tight polytetrafluoroethylene septa. All sample vials received $100 \mu \mathrm{L}$ of the microbial inoculant. Following Zimmerman (2010), $1.0 \mathrm{~mL}$ aqueous nutrient solution consisting of $0.45 \mathrm{M}$ ammonium sulfate and 0.1 $\mathrm{M}$ monopotassium phosphate was added, that is, an amount of $\mathrm{N}$ and $\mathrm{P}$ in excess of what is needed to mineralize all the organic carbon at Redfield stoichiometric ratios. Abiotic controls were the Oak-400 and Oak-650 leachates + inoculant + nutrient mixtures poisoned with $5 \mu \mathrm{L}$ of saturated mercuric chloride $\left(\mathrm{HgCl}_{2}\right)$ solution. Every sample vial was sparged with $\mathrm{CO}_{2}$-free air for 30 min (Airgas Zero Air, CGA-590) with a double needle assembly. Then, the inoculated leachates were placed on a platform shaker table $(60 \mathrm{rpm})$ in the dark inside a Fisher Scientific Isotemp incubator kept at $28{ }^{\circ} \mathrm{C} \pm 5{ }^{\circ} \mathrm{C}$ for a total of 96 days.

\subsection{Carbon Mineralization}

Mineralization of pyDOC was detected as in-situ total inorganic carbon (TIC) in the incubated solutions, and was measured on Days $0,2,5,10,18,26,36,46,66$, and 96 of the incubation. Using a double needle assembly penetrating into the solution, this TIC was sparged with $\mathrm{CO}_{2}$ free air (Airgas Zero Air, CGA-590) and plumbed through a $\mathrm{AgNO}_{3}$ solution and then detected with a $\mathrm{CO}_{2}$ coulometer (UIC, Inc. 5017). This both removes all TIC from solution, and oxygenates the solution prior to further incubation. While no user-calibration is required for this coulometer, the quality of these data was confirmed by routine running of known amounts of $\mathrm{CaCO}_{3}$ and $\mathrm{KHCO}_{3}$ standards which were acidified to produce $\mathrm{CO}_{2}$. The precision of these measurement was $<0.2 \%$ and the analytical detection limit was found to be $0.1 \mu \mathrm{g}$ C. MilliQ water blanks were also incubated and measured using the coulometer to confirm the absence of gas leakage.

\subsection{Dissolved Organic Carbon Analyses}

Aliquots (10 mL) of initial and incubated leachates (Days 0, 10, and 66) were analyzed for DOC content on a Shimadzu TOC-VCSN with high-sensitivity Pt catalyst after acidification to $\mathrm{pH} 2$ (with trace metal grade $\mathrm{HCl}$ ) and sparging for 2 min with $\mathrm{N}_{2}$ to remove inorganic $\mathrm{C}$. Standard curves were generated using potassium biphthalate solutions ranging from 0.4 to $40 \mathrm{mg} \mathrm{C} \mathrm{L}^{-1}$ (Sigma-Aldrich, >99.95\%). These data were used to compare with pyDOC mineralization measured via respired $\mathrm{CO}_{2}$ and to normalize other chemical data (below) to organic carbon content. 


\subsection{BPCA Analyses}

BPCA compounds are produced via the oxidation of condensed aromatic compounds, including both 3 to 4-ring PAH compounds and large condensed aromatic clusters (Ziolkowski et al., 2011). Here, we use changes in $\Sigma$ BPCA-C (the sum of benzenetri-, benzenetetra, benzenepenta- and benzenehexacarboxylic acids, notated as B3CA-C, B4CA-C, B5CA-C and B6CA-C, respectively) as an indicator of biomineralization of all these BPCA-producing compounds as a whole. Given that B3CAs and B4CAs have been found to be produced by non-pyrogenic OM sources (Bostick et al., 2018; Kappenberg et al., 2016), B5CA and B6CA molecules are more robust markers of larger condensed aromatic clusters than total BPCAs. Though a recent study suggests that B5CA and B6CA too may have non-pyrogenic sources (in marine DOC, Wagner et al., 2019), this does not affect the results of this study since purely pyrogenic materials are used. Thus, ConAC content was calculated here as the carbon found in B5CA-C and B6CA-C only, multiplied by a factor of 7.04, as derived previously from graphene oxide oxidation efficiency experiments (Bostick et al., 2018). This factor is needed because a significant loss of carbon occurs during nitric acid oxidation. Trends in the varying proportions of the BPCA compounds are represented here by a benzenepolycarboxylic acid aromatic condensation index (BACon-index, i.e., the average number of carboxyl substitutions among the BPCAs produced). This index has been used previously by Bostick et al. (2018, 2020) and Ziolkowski et al. (2010) as a relative indicator of condensed aromatic cluster size.

Analyses of BPCA were based upon Dittmar (2008) and are described in detail in Bostick et al. (2018). Briefly, $40 \mathrm{~mL}$ aliquots of initial and incubated (Days 10 and 66) leachates were acidified to $\mathrm{pH}$ 2, loaded onto Agilent PPL cartridges ( $3 \mathrm{~mL}, 100 \mathrm{mg}$ ) and eluted with $10 \mathrm{~mL}$ methanol. After drying, the eluents and approximately $0.5 \mathrm{~mL}$ concentrated nitric acid (65\%) were flame-sealed into $1.5 \mathrm{~mL}$ glass ampoules, placed in Parr pressure bombs, and heated to $170{ }^{\circ} \mathrm{C}$ for $9 \mathrm{~h}$. Digested products were concentrated and transferred into Teflon septa-topped vials. BPCA compounds were separated and detected via high performance liquid chromatography (HPLC, Shimadzu LC-20 Prominence Series) equipped with a $\mathrm{C}_{18}$ column $(3.5 \mu \mathrm{m}$, $2.1 \times 150 \mathrm{~mm}$, Waters Sunfire) and a diode array detector (DAD) (Surveyor, Thermo-Scientific, SPD-M20A) using a buffered binary gradient (i.e., $\mathrm{H}_{2} \mathrm{O}$ and methanol-based) program.

\section{7. ${ }^{1}$ H Nuclear Magnetic Resonance Spectroscopy}

Proton nuclear magnetic resonance (NMR) spectroscopy was used to examine the changes in organic functional group distributions of the leachates due to microbial utilization. Initial and 10-day microbially incubated leachates were spiked with sodium 2,2,3,3-tetradeutero-3-trimethylsilylpropanoate (TMSP, Acros Organics, $98 \% \mathrm{D})$ to obtain a $1 \mu \mathrm{M}$ TMSP final concentration, and diluted with deuterated water $\left(\mathrm{D}_{2} \mathrm{O}\right.$, Acros Organics, $100 \%$ D) at the volumetric ratio of 9:1 (i.e., $\mathrm{H}_{2} \mathrm{O}: \mathrm{D}_{2} \mathrm{O}$ ). NMR spectra of these deuterated pyDOM solutions were obtained on a Bruker Biospin AVANCE III $400 \mathrm{MHz}$ NMR spectrometer fitted with a Double Resonance Broadband Inverse probe, at Old Dominion University's College of Sciences Major Instrumentation Cluster (COSMIC) facility. One-dimensional ${ }^{1} \mathrm{H}$ spectra were obtained using a $4 \mathrm{~s}$ relaxation delay, 10,000 scans, and a pulse program performing Perfect-Echo-WATERGATE water suppression (Adams et al., 2013; Whitty et al., 2019), following previous studies (e.g., Wozniak et al., 2013). To correct for matrix effects, a $\mathrm{HgCl}_{2}$-poisoned blank amended with the microbial inoculate and nutrients, was filtered using a $0.2 \mu \mathrm{m}$ membrane filter, and used as a procedural blank which was subtracted from all spectra by normalizing the data to the TMSP peak $(\delta \approx-0.02 \mathrm{ppm})$. The spectra were then integrated over specific chemical shift regions that are characteristic of ${ }^{1} \mathrm{H}$ chemical environments.

The spectra were divided into regions that represent different functional groups as follows. The region between 0.60 and $1.80 \mathrm{ppm}$ (termed "Alkyl-C") includes signals from methyl-H (0.6-1.0 ppm), methylene-H (1.0-1.4 ppm), and $\mathrm{H}$ in alkyl groups that have heteroatoms bound to a beta $\mathrm{C}$ (HC-C-CX, where X is O, N, S, etc., 1.4-1.8 ppm). The regions between 1.8-4.4 ppm and 8.3-10.0 ppm (termed "Oxygenated-C") includes signal from carbonyl and carboxyl functional groups, $\mathrm{H}$ bound to $\mathrm{C}$ bound to $\mathrm{N}$ or $\mathrm{S}$ (HC-N or HC-S, 1.8$3.2 \mathrm{ppm})$, carbohydrate and alcohol groups (HC-OR, 3.2-4.4 ppm) and aldehydes $(\mathrm{O}=\mathrm{CH}, 8.3-10.0 \mathrm{ppm})$. The region between 6.5 and $8.3 \mathrm{ppm}$ (termed "Aryl-C") corresponds to $\mathrm{H}$ attached to aromatic C. Lastly, $\mathrm{H}$ in acetic acid/acetate (1.9-2.1 ppm), methanol (3.2-3.4 ppm) and formic acid (8.1-8.3 ppm) appeared in some spectra as sharp singlet peaks indicative of pure compounds. Signals corresponding to these three regions were summed and reported as 'low molecular weight-C" (LMW-C) compounds, and subtracted from 
the alkyl-C, oxygenated-C, or aryl- $\mathrm{C}$ regions in which their chemical shifts occurred. Not considered is ${ }^{1} \mathrm{H}$ signal between 4.4 and $5.0 \mathrm{ppm}$, which includes some amine and ester $\mathrm{H}$, as the resonances in this region are attenuated by the water suppression pulses.

Spectral signals in each chemical shift region were integrated using the Bruker Topspin software. For a comparison of the NMR data with other quantitative data (e.g., TOC measurements), the ${ }^{1} \mathrm{H}$ NMR spectral assignments were converted to a C-basis following Decesari et al. (2007) by dividing each integrated area by $\mathrm{H} / \mathrm{C}$ ratios typical of the ${ }^{1} \mathrm{H}$ environments in that chemical shift region. The relative contribution of each chemical shift region was then calculated as the C-basis area divided by the sum of all C-basis areas.

\subsection{Replication and Data Analysis}

All leachate types were incubated in quadruplicate until Day 10, when one of each replicate was harvested for BPCA-C analysis and thereupon incubated in triplicate. Significant differences among pyDOC loss amounts and rates (time vs. DOC concentration slopes) were compared for the "early" (Days 0-5) and "late" (Days 46-96) incubation period using Microsoft Excel's t-test function ( $\alpha=0.05$ level). Both TIC and DOC analyses were replicated 5 times and additional analyses were run if coefficients of variation exceeded 5\%. While analyses of BPCA were not replicated for samples collected in this study, previously, four repeated analyses of BPCA-C content in the leachate of a Fresh Oak-400 charcoal using the same method in our laboratory yielded a relative standard deviation of $2.3 \%$.

A first-order exponential decay equation was used to model DOC mineralization kinetics for each leachate such that the following condition was met:

$$
C_{t}=C_{\mathrm{m}_{0}} e^{-k t}+C_{\mathrm{nm}}
$$

where $C_{t}$ is the amount of total pyDOC remaining at time $t, C_{\mathrm{m} 0}$ is the initial concentration of mineralizable pyDOC, $C_{\mathrm{nm}}$ is the amount of non-mineralized carbon (defined as the carbon remaining after 96 days), and $k$ is the apparent first order biomineralization rate constant for the degradable portion of the pyDOC. The non-linear regression tool available on SigmaPlot 14 was used to fit Equation 1 to the incubation data.

\section{Results and Discussion}

\subsection{Biomineralization of pyDOC}

All measurements of carbon mineralization calculated using cumulative evolved $\mathrm{CO}_{2}$ were within $4 \%$ of those calculated using DOC loss at the end of each incubation (Table S2). The extent and rate of fresh pyDOC mineralization was significantly greater in microbial versus abiotic (control) incubations $(p<0.01)$ and varied with parent char temperature (Figure 1). Poisoned controls of Oak-400 and Oak-650 leachates only lost $8 \pm 1 \%$ of its DOC over 96 days of incubation. This provides an estimate of the extent of abiotic oxidation that may occur in the environment, such as, by oxidation of aliphatic carbon by ozone, as has been suggested previously (Cheng et al., 2006; Sergides et al., 1987).

Over the 96-day microbial incubation, significantly more fresh pyDOC was lost from the lower temperature char leachate $(45 \pm 2 \%$ loss from Fresh Oak-400) than from the higher temperature char leachate $(37 \pm 3 \%$ loss from Fresh Oak-650, $p=0.02$ ). These results were expected as Oak-400 char and its leachates are known to contain higher proportions of compounds that are considered to be readily bioavailable (i.e., rich in carbohydrates and LMW compounds, Bostick et al., 2018). Correspondingly, the extent of biomineralization reported here is less than that reported for $250{ }^{\circ} \mathrm{C}$ mesquite char leachate over 37 days (i.e., $60 \%$ carbon loss, Norwood et al., 2013). While the rate of pyDOC loss from the Oak-400 leachate was significantly greater than that from the Oak-650 leachate in the early portion of the incubation (1.8 times greater during the first 5 days), late incubation (between Days 46 and 96) loss rates from Fresh Oak-400 and Oak-650 were not statistically different from each other or from those of the poisoned controls. This supports the postulation of an essentially non-biomineralizable portion of the pyDOM, assumed in the pyDOC degradation model (see Section 3.5 below). 


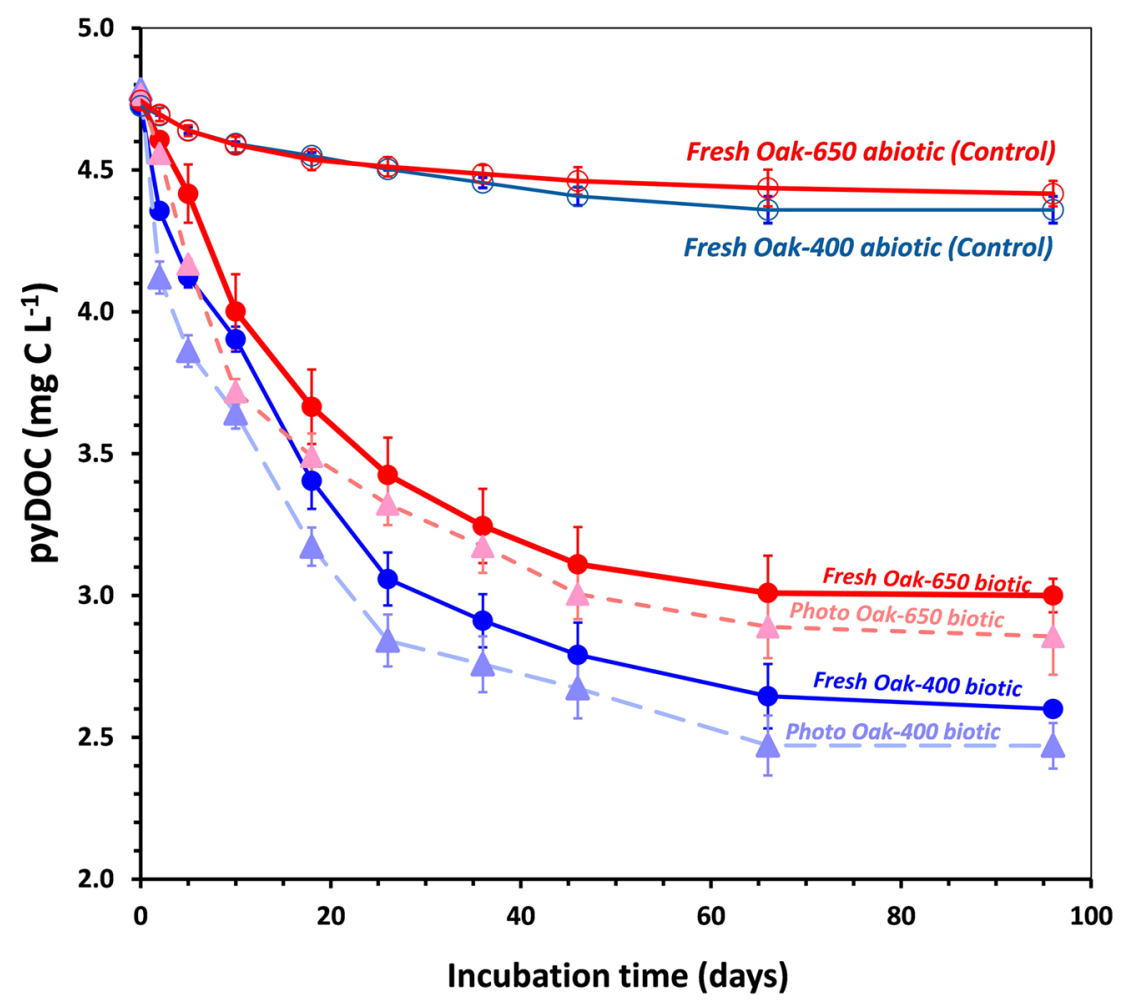

Figure 1. Pyrogenic dissolved organic carbon (pyDOC) concentrations in fresh and photodegraded Oak-400 and Oak650 char leachates during microbial and abiotic incubations. Curves represent the modeled exponential decay (model parameters given in Table 1).

The photodegraded leachates from both chars biomineralized at significantly higher rates than fresh char leachates over the first 5 days (by about 1.5 times; Figure 1). By the end of the incubation (Day 96), pyDOC loss from photodegraded leachates was significantly greater than those from their fresh leachate counterparts (by $10.6 \%$, on average). This phenomenon has been observed with natural DOM where photoexposure increased the microbial mineralization of glacier DOM by roughly $60 \%$ over 35 days (Antony et al., 2018), and photoexposure of dissolved humic substances caused a 1.5 to 6-fold increase in bacterial production (Moran \& Zepp, 1997).

\subsection{Biodegradation of Condensed OM in Fresh Leachates}

Condensed aromatic components of the pyDOM were biomineralized to a much less extent than other constituents of the pyDOM. Approximately $4.4 \%$ and $10.1 \%$ of $\Sigma$ BPCA-C was lost from Fresh Oak-400 and Oak-650 pyDOM, respectively, over 66 days (Figure 2 ). These losses were significantly greater than the $2 \%$ losses of $\Sigma$ BPCA-C from both abiotic incubations over the same period $(p=0.03)$, indicating that most of the degradation of condensed OM was microbially mediated. These low rates of BPCA-yielding OM utilization are on the order of those observed for condensed tannins from soil litter $(0.1 \%-11.0 \%$ over 4 weeks, Nierop et al., 2006), but lower than losses of PAH, that is, $19 \%-53 \%$ over 15 weeks in a simulated sandy soil with white rot fungi (Wolter et al., 1997).

BACon-values of both Fresh Oak-400 and Fresh Oak-650 leachates were initially quite similar (4.0 \pm 0.1$)$. After 66 days of microbial incubation, the BACon-values of these fresh leachates had increased by 0.02 and 0.1 , respectively, indicating that the average size of aromatic clusters in pyDOM increased slightly with microbial incubation (Figure 2). This is also illustrated by a greater reduction in the yields of B3CA + B4CA-C (5.1\% and 15.6\% loss from Oak-400 and Oak-650 leachates, respectively, Figure S4), compared to that of B5CA + B6CA-C (2.2\% and 1.4\%, respectively). The former are derived from all condensed units ( 3 aromatic 


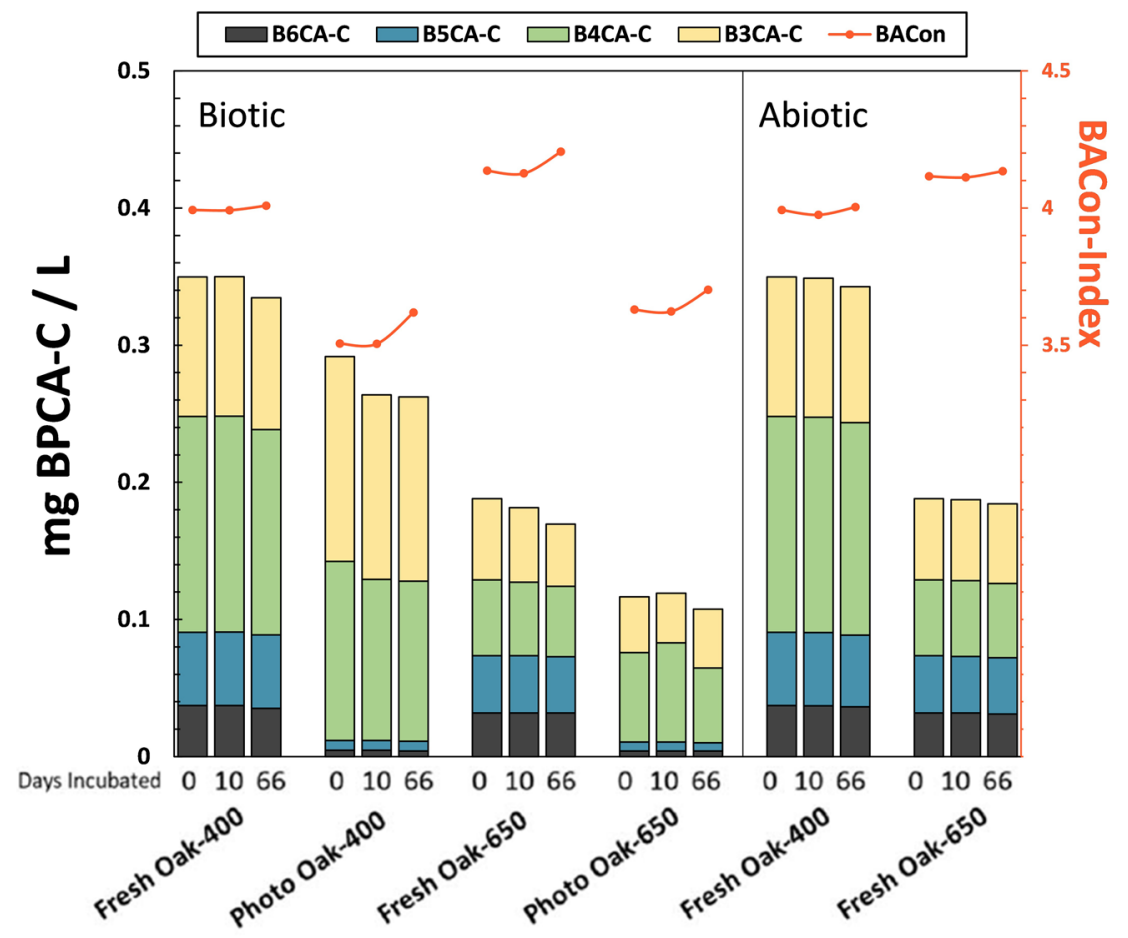

Figure 2. Distribution of BPCA-C compounds produced by initial and incubated (Days 10 and 66) oak char leachates (left $y$-axis, bar graphs) and BACon Index, that is, average number of carboxyl groups among the BPCA compounds, representing degree of aromatic condensation (right $y$-axis, orange data points). BPCA, benzenepolycarboxylic acid; BACon, BPCA aromatic condensation.

rings and larger) whereas the latter are only produced by condensed clusters of $>4$ aromatic rings (Bostick et al., 2018; Ziolkowski et al., 2011).

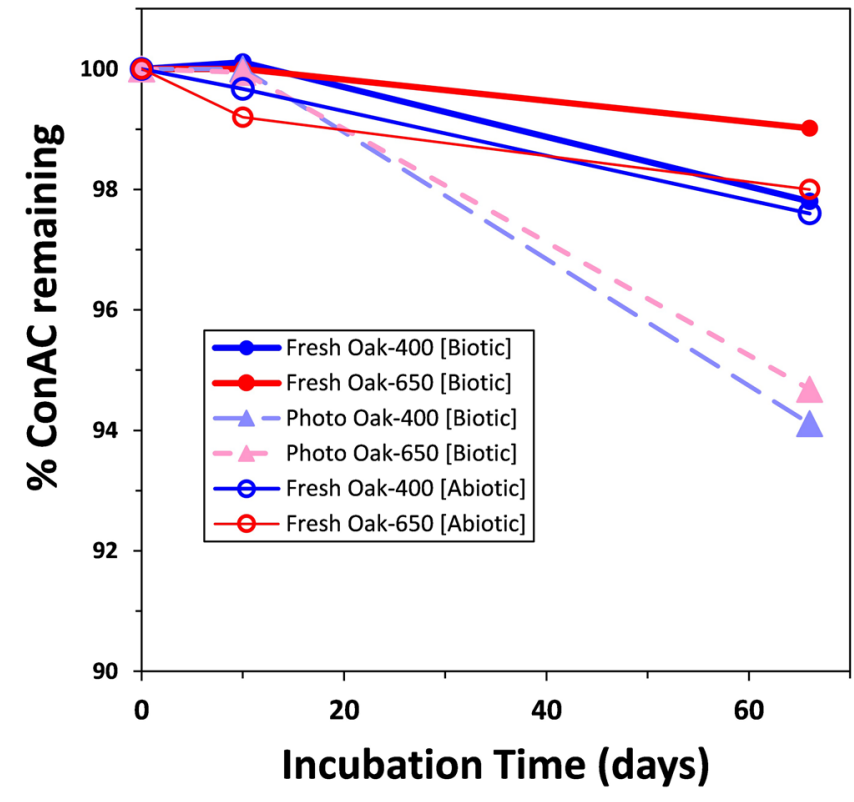

Figure 3. Relative condensed aromatic carbon (ConAC) content (\% of initial ConAC content) of fresh and photodegraded oak char leachates during microbial and abiotic incubations.
These molecular shifts in BPCA-yield can be attributed to mineralization of lower molecular weight condensed compounds, that is, those of smaller cluster size, in preference to larger ones. They explain the greater loss of $\Sigma$ BPCA-C from Oak-400 versus Oak-650 leachates as the former are richer in these smaller condensed compounds. Biolability has previously been shown to scale with the number of aromatic rings in a compound. For example, a study showed that while 2-ring PAHs have half-lives of 10 days in soil, 5-ring PAHs have half-lives that can exceed 200 days (McGinnis et al., 1988; Sims et al., 1988). An alternative explanation is that large clusters of condensed OM were formed during the incubations via microbial or abiotic cyclopolymerization reactions (i.e., similar to those observed under sunlit Fenton conditions by Waggoner et al., 2015). For example, one study detected in situ biological formation of BPCA-yielding compounds in soils (Glaser \& Knorr, 2008). Another study found that the fungus Aspergillus niger yielded BPCA compounds, particularly B6CAs (Brodowski et al., 2005).

The 1.4\%-2.2\% loss of larger aromatic pyDOM over the 66-day incubation (ConAC, calculated using only B5CA and B6CA markers) was similar to the $2.0 \%-2.4 \%$ loss of ConAC from abiotic controls (Figure 3). Thus, a large portion of the losses from microbial incubations can be attributed to abiotic oxidation or, even potentially, to ConAC condensation to colloidal pyDOM. These results indicate that, under these experimental conditions, the pyDOM with the highest degree of condensation (e.g., 


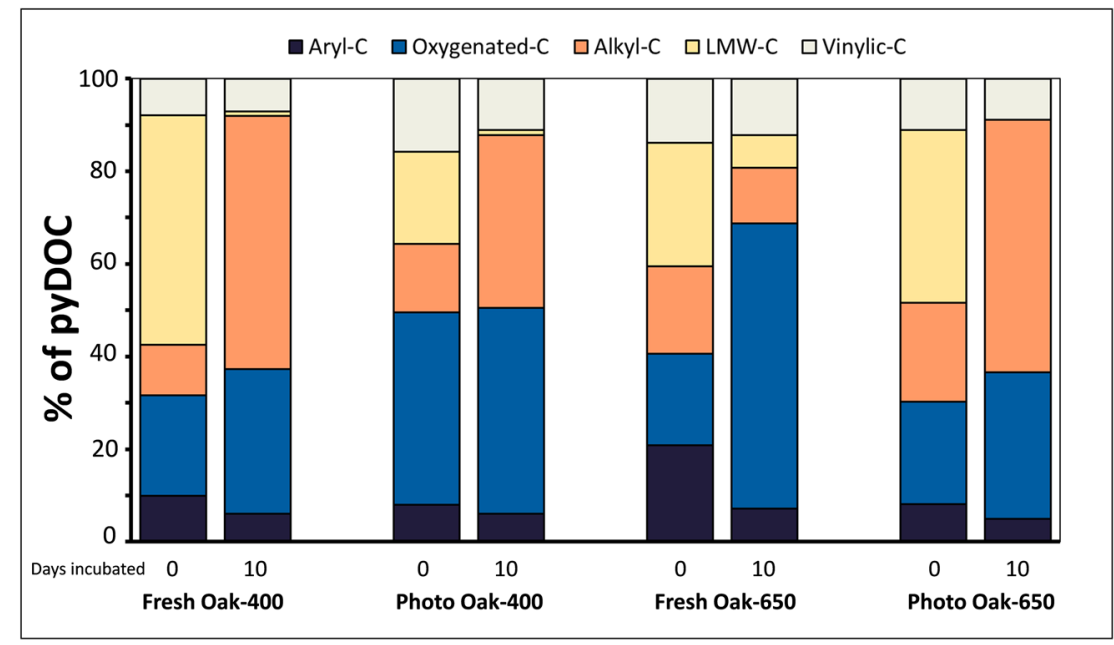

Figure 4. Relative abundance of carbon in different functional groups, calculated using ${ }^{1} \mathrm{H}-\mathrm{NMR}$ data, in initial and 10-day microbially incubated Oak-400 and Oak-650 char leachates. See Section 2.8 of the text for details on chemical group assignment and conversion to $\mathrm{C}$ units.

most aromatic rings) was nearly wholly biorecalcitrant. These results align with those of Kim et al. (2006) in which very little pyrogenic stream DOM detected as hydrogen-deficient molecules with low H:C ratios, was metabolized in biofilm reactors.

\subsection{Biodegradation of Photo-Treated Leachate ConAC}

As has been reported previously with these same char leachates (Bostick et al., 2020), about 10\%-20\% DOC was lost over 5 days of photoincubation while the $\Sigma$ BPCA-C yield decreased by $61 \%-73 \%$. Condensed pyDOC of larger cluster size was most susceptible to photodegradation as indicated by a $73 \%-95 \%$ decrease in yield of B5- and B6CA compounds and an average decrease in BACon values from $4.0 \pm 0.1$ to $3.6 \pm 0.1$ (Figure 2). During the 66 days of microbial incubation, $10.1 \%$ and $7.7 \%$ of $\Sigma B P C A-C$ was lost from the photodegraded Oak-400 and Oak-650 leachates, respectively, which is significantly more (by about 5 times) than what was lost from their fresh leachate counterparts $(p=0.04$, Figure 2). BACon-values of photodegraded Oak-400 and Oak-650 leachate increased by 0.11 and 0.07 , respectively, indicating that the average size of the condensed aromatic clusters in pyDOM increased slightly with microbial incubation. These data further support the conclusion that aromatic compounds with fewer rings were more biolabile than larger ones.

The greater mineralization of pre-photoexposed pyDOM (compared to fresh pyDOM) can be explained by its lower condensed carbon ( $\mathrm{B} B \mathrm{CA}-\mathrm{C}$ and ConAC) content. Further, the greater mineralization of the condensed portion in pre-photoexposed pyDOM can be explained by its relatively greater proportion of smaller sized aromatic clusters (Figure 2). Another possibility is that "photopriming" occurred, whereby photoexposure created labile compounds that stimulated the production of microbial enzymes, leading to the enhanced biomineralization of more refractory components. Priming of solid pyrogenic matter due to the presence of more labile non-pyrogenic organic components has been observed previously (Zimmerman \& Ouyang, 2019; Zimmerman et al., 2011) and photoexposure has been found to stimulate the biomineralization of otherwise refractory leaf litter lignin (Austin et al., 2016; Lin et al., 2018).

\subsection{Functional Group Composition of Fresh and Degraded pyDOM}

After 10 days of microbial incubation of pyDOM, carbon present in low molecular weight (LMW) organic components (e.g., formate, formic acid, methanol, acetate, and acetic acid), which initially constituted $20 \%-50 \%$ of pyDOC, was almost entirely consumed (Figure 4 and Table S3). Methanol and formate were likely mineralized by methylotrophic bacteria and/or methylotrophic fungi, the only microbes known to consume C1 constituents of DOM (Chistoserdova \& Kalyuzhnaya, 2018; Chistoserdova et al., 2003; Kolb \& Stacheter, 2013). These methylotrophs have previously been identified in the soil microbiome used in 
Table 1

First-Order Exponential Decay Model Parameters for Mineralizable pyDOC Portion (All With Fits $r^{2}>0.98$ )

\begin{tabular}{lcrr}
\hline Leachate & $\begin{array}{c}\text { Modeled mineralizable pyDOC } \\
\text { fraction }(\%)\end{array}$ & $k\left(y^{-1}\right)$ & $\begin{array}{r}t_{1 / 2} \\
(d)\end{array}$ \\
\hline Fresh Oak-400 biotic & 45 & 19.72 & 12.4 \\
Photo Oak-400 biotic & 48 & 27.05 & 9.3 \\
Fresh Oak-650 biotic & 37 & 18.94 & 13.4 \\
Photo Oak-650 biotic & 41 & 22.74 & 11.0 \\
Fresh Oak-400 abiotic & 7 & 13.84 & 18.3 \\
Fresh Oak-650 abiotic & 8 & 19.10 & 13.2 \\
\hline
\end{tabular}

Notes. $k=$ first-order loss rate constant of the biodegradable portion; $t_{1 / 2}=$ the half-life of the mineralizable pyDOC in the experimental system. this study (e.g., Methylococcaceae and Methylobacteriaceae, Khodadad et al., 2011). Formic and acetic acids have been previously demonstrated to be readily bioavailable to heterotrophic bacteria (i.e., turnover rate constants $\sim 0.2$ h, Herlihy et al., 1987). In addition to these LMW constituents, there was a $25 \%-67 \%$ relative decrease in aryl-C over the same period in all leachates, indicating a sizable decrease in the pyDOM's aromatic content. This aromatic pyDOM could have been degraded by both $\alpha$ - and $\gamma$-Proteobacteria, which are known to degrade lignin using lignin peroxidase and manganese peroxidase enzymes (Tian et al., 2014). These taxa have also previously been identified in the microbial consortium used in this study (Khodadad et al., 2011). The proportion of aryl-C losses were considerably greater than those of $\mathrm{BPCA}-\mathrm{C}$ suggesting that much of the aryl- $\mathrm{C}$ in these samples contain fewer than 3 aromatic rings and provides further evidence for an inverse relationship between biolability and the number of aromatic rings in a compound.

After 10 days of microbial incubation, the remaining pyDOC was mainly composed of oxygenated-C and alkyl-C (e.g., methyl-C, methylene-C, and aliphatic compounds bonded with $\mathrm{O}, \mathrm{N}$, and $\mathrm{S}$ ) with smaller portions of vinylic-C (Table S3). It is likely that these groups represent thermally altered cellulose components, which require extensive enzymatic degradation before they can be utilized (Payne et al., 2015).

Compared to the fresh pyDOM leachates, photodegraded leachates were relatively depleted in aryl-C and enriched in oxygenated-C components (Figure 4). While the LMW component of Oak-400 decreased with photoexposure, that of Oak-650 increased. These results are consistent with previous findings that photodegradation of pyDOM converts condensed aromatic units (which were of more relative abundance in Oak650 pyDOM) into smaller aromatic and aliphatic compounds (Bostick et al., 2020).

Biodegradation of the photodegraded pyDOM samples yielded patterns of relative functional group change similar to those of fresh pyDOM samples, namely: nearly total loss of LMW-C, decreased aryl-C, increased oxygenated- and alkyl-C. Thus, it is likely that photodegradation increased the rate and extent of pyDOC biomineralization by breaking large compounds, including condensed aromatics, into LMW and other more easily metabolizable components. This is supported by previous studies which show rapid utilization of small compounds such as LMW organic acids produced by photolysis of even recalcitrant DOM (Brinkmann et al., 2003; Wetzel et al., 1995).

\section{5. pyDOM Biomineralization Kinetics and Mechanisms}

Longer-term estimates of pyDOC bioavailability are needed to understand the residence time of pyC in different pools, the potential for export of pyC from land to ocean, and to provide parameters needed for global pyC cycling models. The majority of biomineralization occurred early in the incubations with about $80 \%$ of all pyDOC loss occurring in the first 26 days of the biotic incubations (and 20\% lost in the remaining $70 \mathrm{~d}$ ). As pointed out above, rates of mineralization in the later incubation period were low ( $\sim 0.1 \%$ daily loss), and not significantly different from the abiotic control. This supports the assumption, for the purpose of modeling, of two pyDOM components: (1) a relatively biolabile portion that is readily biomineralizable, and (2) a pyDOM portion that does not biomineralize under the experimental conditions (i.e., is mineralized at rates indistinguishable from those of the abiotic controls).

The loss of the mineralizable portion of the pyDOC was successfully simulated using a single-component exponential decay equation (Equation 1 , all $r^{2}$ values $\geq 0.98$, Table 1 ). A two-component decay equation did not simulate the data substantially better (i.e., did not yield significantly higher $r^{2}$ values). This suggests that compared to solid pyrogenic solids whose degradation kinetics simulation commonly requires a 2-component model (e.g., Fang et al., 2014; Zimmerman, 2010), the dissolved pyC may be more uniformly available to microbes.

Using the single-component model, the biomineralizable fraction of fresh pyDOM was calculated to have experimental half-lives of approximately 12-13 days and accounted for approximately $45 \%$ and $37 \%$ of the 
total DOC in Fresh Oak-400 and Oak-650 leachate, respectively. These fractions roughly corresponded to the estimated amount of pyDOC initially present as LMW-C (i.e., 50\% and 27\%, respectively), the component lost to the greatest extent during microbial incubation, as determined by ${ }^{1} \mathrm{H}-\mathrm{NMR}$ spectroscopy data. Thus, the majority of carbon loss could be attributed to LMW-C mineralization. The half-lives of this biomineralizable fraction are slightly longer than the half-lives of other non-condensed components of pyDOM from lightly charred biomass. For example, levoglucosan and free lignin phenols were shown to have half-lives of 4 and 5 days, respectively (Norwood et al., 2013). These shorter half-lives are likely due to the molecular-level lability of these components rather than their lower thermal maturity, as the bioavailable portions of the $400^{\circ} \mathrm{C}$ and $650^{\circ} \mathrm{C}$ char pyDOM were found to have similar half-lives (Table 1).

The biorecalcitrant pyDOM accounted for approximately 55\% and 63\% of the total pyDOC in Fresh Oak400 and Oak-650 leachates, respectively. Given that ConAC was largely resistant to degradation (only 2\% loss over 66 days), it is clear that ConAC constitutes a portion of this recalcitrant pyDOM fraction. However, given the amounts present in pyDOM, ConAC can only account for 5\%-25\% this biorecalcitrant fraction. Thus, the remaining 75\%-95\% of this biorecalcitrant fraction must be made up of small aromatic compounds (<4 rings) and non-aromatic compounds, the latter of which, according to the ${ }^{1} \mathrm{H}-\mathrm{NMR}$ data, was primarily composed of oxygenated and alkylated carbon. While oxygenated and alkylated forms of compounds are not generally thought to be biorefractory, it is possible that the presence of phenolic or condensed compounds inhibited microbial enzyme synthesis or activity, decreasing the microbial utilization of this otherwise biolabile DOM. This may be similar to the inhibitory effect of phenolic and aromatic substances on labile aquatic DOM mineralization observed by Mann et al. (2014), Tejirian and Xu (2011), and Backes et al. (1993) in aquatic settings. Some pyDOM compounds may also become microbially inaccessible through their complexation with metals or colloids (Marschner \& Kalbitz, 2003). More specifically, oxygenated and alkyl DOM have been shown to chemically bind with DOM components (Guggenberger et al., 1994; Jandl \& Sollins, 1997), which can shield them from enzymatic attack. Thus, it may be that interactions between the many organic and inorganic components leaching from the pyrogenic solids resulted in their inaccessibility to microbial mineralization, as opposed to their intrinsic chemical recalcitrance.

The biomineralizable fraction of photodegraded Oak-400 and Oak-650 leachates degraded only slightly faster than their fresh counterparts (i.e., experimental $t_{1 / 2}$ of approximately 9 and 11 days, respectively). This mineralizable fraction represented approximately $48 \%$ and $41 \%$ of Photo Oak-400 and Photo Oak-650 leachates, respectively. Unlike the fresh leachates, the amount of the biomineralizable component in photo-treated samples was somewhat greater than the amount of pyDOC initially present as LMW-C (i.e., about $20 \%$ and $37 \%$ in Photo Oak-400 and Oak-650, respectively), as estimated from ${ }^{1} \mathrm{H}-\mathrm{NMR}$ spectroscopy data. Thus, unlike for the fresh leachates, there must have been considerable carbon mineralization in the photo-treated leachates (particularly that of Photo Oak-400) that were not attributable to LMW compounds. Using a carbon mass balance calculation approach, one study indicated that, in addition to LMW compound production, higher molecular weight compounds might also be altered by light exposure so that their biolability is increased (Miller \& Moran, 1997). Thus, the term "photolabilization" could be broadly applied to the experimental results. As discussed above, photopriming may also have occurred, but it cannot be confirmed with the current data.

The biorecalcitrant portion accounted for approximately 52\% and 59\% of the total pyDOC in Photo Oak400 and Oak-650 leachates, respectively. However, ConAC could, at most, only account for about $3 \%$ of this biorecalcitrant fraction as the majority of ConAC was lost during photodegradation. These proportions are somewhat less than those noted above for non-photoexposed pyDOC and further suggest some mechanism, such as humic or metal interaction, whereby compounds thought of as biolabile were shielded from mineralization. In any case, photoexposure did not increase the recalcitrant of pyDOM, as it did in a mixture of humic matter and algae-derived DOM (Tranvik \& Kokalj, 1998).

\subsection{Implications and Environmental Significance}

The use of a soil microbial consortium inoculant in these experiments implies that the measured rates of pyC degradation apply to pyC present in a soil or vadose zone environment. In contrast, photoexposure of the dissolved pyC, which we have found to make pyDOM more biologically assessable, would predominantly occur in aquatic environments. However, soil microbes are more diverse than, and often transferred 
to, adjacent aquatic systems (Crump et al., 2012), and the soil microbial inoculate used was from a heavily burned pine upland, and so may have developed strategies for metabolizing or transforming pyOM. Thus, we considered our approach (i.e., the combination of soil microbes and photoexposure) to provide a sense of the maximum biotic loss likely to occur in any environment.

In terms of biodegradability, about $40 \%-50 \%$ of the pyDOC in this study was lost over 90 days. This generally falls between the large proportion of fresh biomass leachate that is commonly lost in microbial incubation experiments and the small portion of soil DOM lost over similar time periods. For example, $56 \%-84 \%$ of algal DOC (Lee et al., 2016), 35\%-95\% of forest throughfall DOC (Qualls \& Haines, 1992) and 61\%-93\% of leaf litter and straw leachate DOC (Kalbitz, Schmerwitz, et al., 2003; Strauss \& Lamberti, 2002) was lost over 60, 134, and 24 days of incubation, respectively. In contrast, DOC mineralized from mineral soils ranges from $1 \%$ to $20 \%$ over similar periods (e.g., Qualls \& Haines, 1992; Schwesig et al., 2003; Vujinović et al., 2019). Thus, the pyrolysis of biomass can be likened to soil processes, such as OM decomposition and humification, which make the DOM derived from soil OM progressively less biodegradable (Kalbitz, Schmerwitz, et al., 2003). As with soil DOM, pyDOM biodegradability is also likely closely related to its chemical properties, decreasing with aromaticity, degree of condensation (Kalbitz, Schmerwitz, et al., 2003; Kalbitz, Schwesig, et al., 2003), and generally increasing with the availability of LMW compounds (van Hees et al., 2005).

The $40 \%-50 \%$ of the pyDOC found to be readily bioavailable in this study represents only a sense of the proportion of pyDOC that might be expected to be lost within the soil vadose zone, preventing its export by rivers to the ocean. Exposure to sunlight, that is, photolysis, will further expedite pyC biomineralization, as it increases the bioavailability of pyDOM, mainly by converting condensed pyDOM to non-condensed compounds. About $50 \%-60 \%$ of pyDOC (whether fresh or photodegraded or from low or high temperature parent solids) resisted biomineralization over the course of the 14-week experiment. Surprisingly, this refractory portion was not primarily composed of condensed OM. In a soil matrix, this pyDOM may be protected from biomineralization to even greater extents, as compounds are adsorbed to clay minerals, or interact with natural humic matter. On the other hand, pyDOM may be degraded to a larger extent in the soil environment due to more favorable conditions there because of wider microbial consortia, or the occurrence of priming by a more labile soil DOM component.

\section{Conclusions}

The generalizability of the finding of this study are limited by the use of laboratory incubations (rather than within a soil solution or water bodies), laboratory-made pyrogenic materials, and use of a specific soil microbial inoculum. However, their value is increased when viewed in the context of a series of studies that used the same set of laboratory-produced chars and char leachates. These studies followed pyDOM from its production (Bostick et al., 2018) to its photo- (Bostick et al., 2020; Goranov et al., 2020) and bio-degradation (this study) can be generalized in a single figure (Figure 5). An overall conclusion is that, while the aromatic fraction $(10 \%-21 \%$ of the pyDOC initially leached) can be rapidly lost to photomineralization (about half the aryl $\mathrm{C}$ and up to $95 \%$ of the ConAC fraction lost over 5 days), and an LMW fraction is likely to be lost to biomineralization $(40 \%-50 \%$ of the pyDOC), it is largely the alkyl and O-functionalized C fraction that is most likely to escape immediate mineralization and be exported to the ocean.

The majority of the past pyDOM cycling studies have used BPCA and high resolution mass spectroscopic analyses of environmental samples (e.g., Ding et al., 2013; Dittmar et al., 2012; Kaal et al., 2016; Stubbins, Niggemann, \& Dittmar, 2012; Ward et al., 2017; Ziolkowski et al., 2011). Consequently, most of our prior knowledge of pyDOM biodegradation has focused only on the condensed portion of pyDOM. The results of this study emphasize the need to understand mineralization rates of bulk pyDOC along with the condensed portion, as there are important differences, interactions, and transfers between these pools. Unfortunately, we do not yet have a way of distinguishing pyrogenic from non-pyrogenic sources of non-condensed pyDOM in natural samples. It is hoped that tracers (biomarker compounds) may be discovered so that pyDOC can be followed through the environment and its influence on the global carbon cycling can be modeled. However, results of this study can already help to refine estimates of pyC contributions to global carbon cycling budgets and models. 


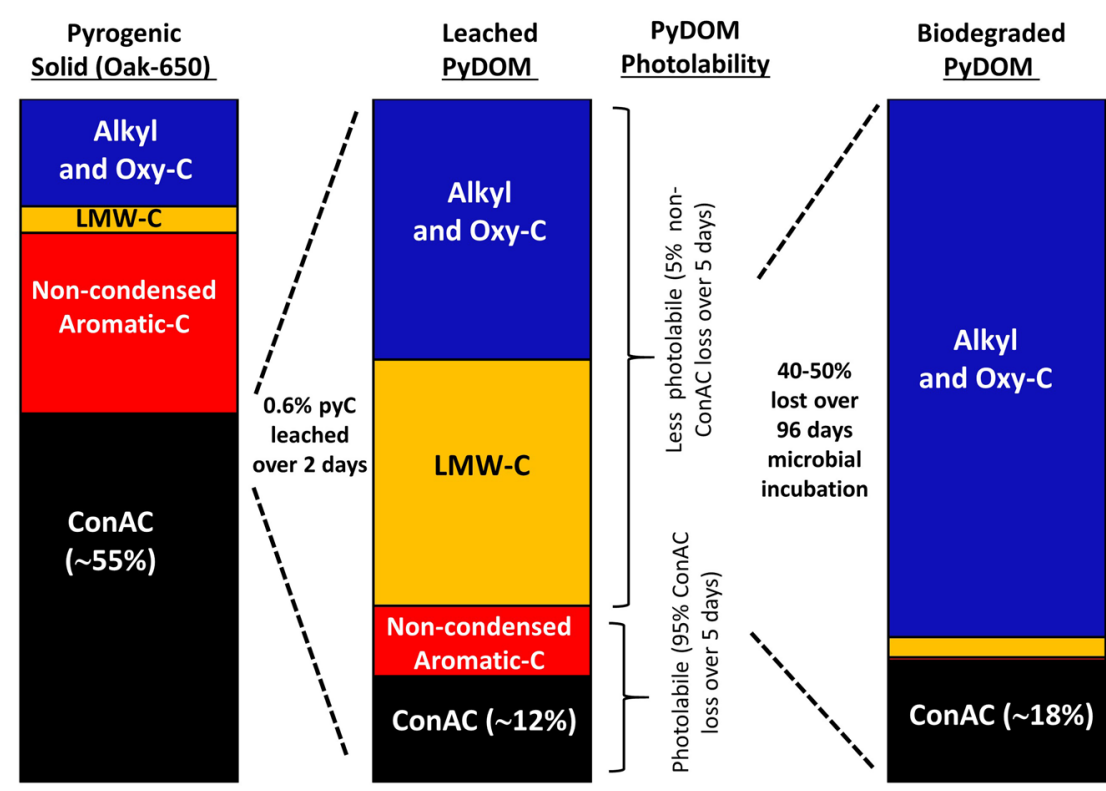

Summary diagram showing generalized trends in production and transformation of pyrogenic carbon via leaching, and photo- and biodegradation.

Figure 5. Summary diagram showing generalized trends in the production (from Bostick et al., 2018) and transformation of pyDOM via photo- (from Bostick at al., 2020) and biodegradation (this study). Relative abundance of functional group carbon is calculated using ${ }^{1} \mathrm{H}-\mathrm{NMR}$ data, reported on a carbon basis as well as ConAC which is estimated using B5CA and B6CA molecular markers. ConAC, condensed aromatic carbon; NMR, nuclear magnetic resonance; pyDOM, pyrogenic dissolved organic matter.

Both the increased application of biochar to soils and frequency of wildfires, and prescribed burning may increase the delivery of pyDOM to aquatic systems. The expected increase in biolabile pyDOM may expedite non-pyrogenic DOM mineralization through priming, while other pyDOM components may bind to both organic and metallic contaminants and assist in their transport through the environment. Further studies are needed to explore (1) molecular-level changes in pyDOM during microbial utilization; (2) interactions between pyDOM and non-pyrogenic DOM that may either increase or decrease their bio-utilization; and (3) changes in pyDOM composition that may be used to indicate the degree to which pyDOM is altered by microbial processes in natural systems.

\section{Data Availability Statement}

Additional data and figures related to this article are available in the accompanying Supplemental Information. Raw data can be downloaded from https://figshare.com/s/99e0c08d84709b48f3fe.

\section{Acknowledgments}

This work was funded by the U.S. National Science Foundation-Geobiology and Low-Temperature Geochemistry Program (EAR-1451367). The authors thank Jason Curtis for his help with colorimetric analyses and the ODU COSMIC facility for assistance with ${ }^{1}$ H NMR measurements. Lastly, the authors thank UF Geological Science department engineer Dow Van Arnam for helping with the construction of the incubation apparatus.

\section{References}

Abiven, S., Hengartner, P., Schneider, M. P. W., Singh, N., \& Schmidt, M. W. I. (2011). Pyrogenic carbon soluble fraction is larger and more aromatic in aged charcoal than in fresh charcoal. Soil Biology and Biochemistry, 43(7), 1615-1617. https://doi.org/10.1016/j. soilbio.2011.03.027

Adams, R. W., Holroyd, C. M., Aguilar, J. A., Nilsson, M., \& Morris, G. A. (2013). "Perfecting” WATERGATE: Clean proton NMR spectra from aqueous solution. Chemical Communications, 49(4), 358-360. https://doi.org/10.1039/c2cc37579f

Amon, R. M. W., \& Benner, R. (1996). Photochemical and microbial consumption of dissolved organic carbon and dissolved oxygen in the Amazon River system. Geochimica et Cosmochimica Acta, 60(10), 1783-1792. https://doi.org/10.1016/0016-7037(96)00055-5

Andrews, S. S., Caron, S., \& Zafiriou, O. C. (2000). Photochemical oxygen consumption in marine waters: A major sink for colored dissolved organic matter? Limnology \& Oceanography, 45, 267-277. https://doi.org/10.4319/lo.2000.45.2.0267

Anesio, A. M., Denward, C., Tranvik, L., \& Granéli, W. (1999). Decreased bacterial growth on vascular plant detritus due to photochemical modification. Aquatic Microbial Ecology, 17, 159-165. https://doi.org/10.3354/ame017159

Anesio, A. M., Granéli, W., Aiken, G. R., Kieber, D. J., \& Mopper, K. (2005). Effect of humic substance photodegradation on bacterial growth and respiration in lake water. Aemilianense, 71(10), 6267-6275. https://doi.org/10.1128/aem.71.10.6267-6275.2005 
Antony, R., Willoughby, A. S., Grannas, A. M., Catanzano, V., Sleighter, R. L., Thamban, M., \& Hatcher, P. G. (2018). Photo-biochemical transformation of dissolved organic matter on the surface of the coastal East Antarctic ice sheet. Biogeochemistry, 141, 229-247. https:// doi.org/10.1007/s10533-018-0516-0

Austin, A. T., Méndez, M. S., \& Ballaré, C. L. (2016). Photodegradation alleviates the lignin bottleneck for carbon turnover in terrestrial ecosystems. Proceedings of the National Academy of Sciences of the United States of America, 113(16), 4392-4397. https://doi. org/10.1073/pnas.1516157113

Backes, W. L., Cawley, G., Eyer, C. S., Means, M., Causey, K. M., \& Canady, W. J. (1993). Aromatic hydrocarbon binding to cytochrome P450 and other enzyme binding sites: are hydrophobic compounds drawn into the active site or pushed from the aqueous phase? Archives of Biochemistry and Biophysics, 304(1), 27-37. https://doi.org/10.1006/abbi.1993.1317

Baldock, J. A., \& Smernik, R. J. (2002). Chemical composition and bioavailability of thermally altered Pinus resinosa (Red pine) wood. Organic Geochemistry, 33(9), 1093-1109. https://doi.org/10.1016/s0146-6380(02)00062-1

Bamforth, S. M., \& Singleton, I. (2005). Bioremediation of polycyclic aromatic hydrocarbons: Current knowledge and future directions Journal of Chemical Technology \& Biotechnology, 80(7), 723-736. https://doi.org/10.1002/jctb.1276

Benner, R., \& Biddanda, B. (1998). Photochemical transformations of surface and deep marine dissolved organic matter: Effects on bacterial growth. Limnology \& Oceanography, 43, 1373-1378. https://doi.org/10.4319/lo.1998.43.6.1373

Bird, M. I., Moyo, C., Veenendaal, E. M., Lloyd, J., \& Frost, P. (1999). Stability of elemental carbon in a savanna soil. Global Biogeochemical Cycles, 13(4), 923-932. https://doi.org/10.1029/1999gb900067

Boerner, R. E. J., \& Brinkman, J. A. (2003). Fire frequency and soil enzyme activity in southern Ohio oak-hickory forests. Applied Soil Ecology, 23(2), 137-146. https://doi.org/10.1016/s0929-1393(03)00022-2

Bostick, K. W., Zimmerman, A. R., Goranov, A., Mitra, S., Hatcher, P. G., \& Wozniak, A. S. (2020). Photolability of pyrogenic dissolved organic matter from a thermal series of laboratory-prepared chars. The Science of the Total Environment, 724, 1-9. https://doi.org/10.1016/j. scitotenv.2020.138198

Bostick, K. W., Zimmerman, A. R., Wozniak, A. S., Mitra, S., \& Hatcher, P. G. (2018). Production and composition of pyrogenic dissolved organic matter from a logical series of laboratory-generated chars. Frontiers in Earth Science, 6, 1-14. https://doi.org/10.3389/ feart.2018.00043

Brinkmann, T., Hörsch, P., Sartorius, D., \& Frimmel, F. H. (2003). Photoformation of low-molecular-weight organic acids from brown water dissolved organic matter. Environmental Science \& Technology, 37(18), 4190-4198. https://doi.org/10.1021/es0263339

Brodowski, S., Rodionov, A., Haumaier, L., Glaser, B., \& Amelung, W. (2005). Revised black carbon assessment using benzene polycarboxylic acids. Organic Geochemistry, 36(9), 1299-1310. https://doi.org/10.1016/j.orggeochem.2005.03.011

Bruun, E. W., Ambus, P., Egsgaard, H., \& Hauggaard-Nielsen, H. (2012). Effects of slow and fast pyrolysis biochar on soil C and N turnover dynamics. Soil Biology and Biochemistry, 46, 73-79. https://doi.org/10.1016/j.soilbio.2011.11.019

Bruun, S., Jensen, E. S., \& Jensen, L. S. (2008). Microbial mineralization and assimilation of black carbon: Dependency on degree of thermal alteration. Organic Geochemistry, 39(7), 839-845. https://doi.org/10.1016/j.orggeochem.2008.04.020

Cheng, C.-H., Lehmann, J., Thies, J. E., Burton, S. D., \& Engelhard, M. H. (2006). Oxidation of black carbon by biotic and abiotic processes. Organic Geochemistry, 37(11), 1477-1488. https://doi.org/10.1016/j.orggeochem.2006.06.022

Chistoserdova, L., Chen, S.-W., Lapidus, A., \& Lidstrom, M. E. (2003). Methylotrophy in Methylobacterium extorquens AM1 from a genomic point of view. Journal of Bacteriology, 185(10), 2980-2987. https://doi.org/10.1128/jb.185.10.2980-2987.2003

Chistoserdova, L., \& Kalyuzhnaya, M. G. (2018). Current trends in methylotrophy. Trends in Microbiology, 26, 703-714. https://doi. org/10.1016/j.tim.2018.01.011

Crump, B. C., Amaral-Zettler, L. A., \& Kling, G. W. (2012). Microbial diversity in arctic freshwaters is structured by inoculation of microbes from soils. The ISME Journal, 6, 1629-1639. https://doi.org/10.1038/ismej.2012.9

Cusack, D. F., Chadwick, O. A., Hockaday, W. C., \& Vitousek, P. M. (2012). Mineralogical controls on soil black carbon preservation. Global Biogeochemical Cycles, 26, 1-10. https://doi.org/10.1029/2011gb004109

da Cunha-Santino, M. B., \& Bianchini, I. (2002). Humic substance mineralization in a tropical oxbow lake (Sao Paulo, Brazil). Hydrobiologia , 468(1-3), 33-43. https://doi.org/10.1023/a:1015214005279

Decesari, S., Mircea, M., Cavalli, F., Fuzzi, S., Moretti, F., Tagliavini, E., \& Facchini, M. C. (2007). Source attribution of water-soluble organic aerosol by nuclear magnetic resonance spectroscopy. Environmental Science \& Technology, 41(7), 2479-2484. https://doi.org/10.1021/ es0617111

Ding, Y., Cawley, K. M., da Cunha, C. N., \& Jaffe, R. (2014). Environmental dynamics of dissolved black carbon in wetlands. Biogeochemistry, 119(1-3), 259-273. https://doi.org/10.6084/m9.figshare.5571679.v4

Ding, Y., Yamashita, Y., Dodds, W. K., \& Jaffé, R. (2013). Dissolved black carbon in grassland streams: Is there an effect of recent fire history? Chemosphere, 90(10), 2557-2562. https://doi.org/10.1016/j.chemosphere.2012.10.098

Ding, Y., Yamashita, Y., Jones, J., \& Jaffe, R. (2015). Dissolved black carbon in boreal forest and glacial rivers of central Alaska: Assessment of biomass burning versus anthropogenic sources. Biogeochemistry, 123(1-2), 15-25. https://doi.org/10.1007/s10533-014-0050-7

Dittmar, T. (2008). The molecular level determination of black carbon in marine dissolved organic matter. Organic Geochemistry, 39, 396-407. https://doi.org/10.1016/j.orggeochem.2008.01.015

Dittmar, T., de Rezende, C. E., Manecki, M., Niggemann, J., Coelho Ovalle, A. R., Stubbins, A., \& Bernardes, M. C. (2012). Continuous flux of dissolved black carbon from a vanished tropical forest biome. Nature Geoscience, 5(9), 618-622. https://doi.org/10.1038/ngeo1541

Fang, Y., Singh, B., Singh, B. P., \& Krull, E. (2014). Biochar carbon stability in four contrasting soils. European Journal of Soil Science, 65(1), 60-71. https://doi.org/10.1111/ejss.12094

Fu, H., Liu, H., Mao, J., Chu, W., Li, Q., Alvarez, P. J. J., et al. (2016). Photochemistry of dissolved black carbon released from biochar: Reactive oxygen species generation and phototransformation. Environmental Science \& Technology, 50(3), 1218-1226. https://doi. org/10.1021/acs.est.5b04314

Glaser, B., \& Knorr, K.-H. (2008). Isotopic evidence for condensed aromatics from non-pyrogenic sources in soils-Implications for current methods for quantifying soil black carbon. Rapid Communications in Mass Spectrometry, 22(7), 935-942. https://doi.org/10.1002/ rcm. 3448

Goranov, A. I., Wozniak, A. S., Bostick, K. W., Zimmerman, A. R., Mitra, S., \& Hatcher, P. G. (2020). Photochemistry after fire: Structural transformations of pyrogenic dissolved organic matter elucidated by advanced analytical techniques. Geochimica et Cosmochimica Acta, 290, 271-292. https://doi.org/10.1016/j.gca.2020.08.030

Guggenberger, G., Zech, W., \& Schulten, H.-R. (1994). Formation and mobilization pathways of dissolved organic matter: Evidence from chemical structural studies of organic matter fractions in acid forest floor solutions. Organic Geochemistry, 21, 51-66. https://doi.org/10.1016/0146-6380(94)90087-6 
Helms, J. R., Stubbins, A., Ritchie, J. D., Minor, E. C., Kieber, D. J., \& Mopper, K. (2008). Absorption spectral slopes and slope ratios as indicators of molecular weight, source, and photobleaching of chromophoric dissolved organic matter. Limnology \& Oceanography, 53(3), 955-969. https://doi.org/10.4319/lo.2008.53.3.0955

Herlihy, L. J., Galloway, J. N., \& Mills, A. L. (1987). Bacterial utilization of formic and acetic acid in rainwater. Atmospheric Environment, 21(11), 2397-2402. https://doi.org/10.1016/0004-6981(87)90374-x

Higuchi, T. (2004). Microbial degradation of lignin: Role of lignin peroxidase, manganese peroxidase, and laccase. Proceedings of the Japan Academy Series B Physical and Biological Sciences, 80(5), 204-214. https://doi.org/10.2183/pjab.80.204

Jaffé, R., Ding, Y., Niggemann, J., Vahatalo, A. V., Stubbins, A., Spencer, R. G. M., et al. (2013). Global charcoal mobilization from soils via dissolution and riverine transport to the oceans. Science, 340(6130), 345-347. https://doi.org/10.1126/science.1231476

Jandl, R., \& Sollins, P. (1997). Water-extractable soil carbon in relation to the belowground carbon cycle. Biology and Fertility of Soils, 25, 196-201. https://doi.org/10.1007/s003740050303

Johns, G. (2016). Austin Cary Forest prescribed burn, 33/8S/21E (pp. 1-5). Prescribed Burn Prescription, School of Forest Resources and Conservation, UF/IFAS

Jones, M. W., Coppola, A. I., Santín, C., Dittmar, T., Jaffé, R. Y., Doerr, S. H., \& Quine, T. A. (2020). Fires prime terrestrial organic carbon for riverine export to the global oceans. Nature Communications, 11, 2791. https://doi.org/10.1038/s41467-020-16576-Z

Kaal, J., Wagner, S., \& Jaffé, R. (2016). Molecular properties of ultrafiltered dissolved organic matter and dissolved black carbon in headwater streams as determined by pyrolysis-GC-MS. Journal of Analytical and Applied Pyrolysis, 118, 181-191. https://doi.org/10.1016/j. jaap.2016.02.003

Kalbitz, K., Schmerwitz, J., Schwesig, D., \& Matzner, E. (2003). Biodegradation of soil-derived dissolved organic matter as related to its properties. Geoderma, 113(3), 273-291. https://doi.org/10.1016/s0016-7061(02)00365-8

Kalbitz, K., Schwesig, D., Schmerwitz, J., Kaiser, K., Haumaier, L., Glaser, B., et al. (2003). Changes in properties of soil-derived dissolved organic matter induced by biodegradation. Soil Biology and Biochemistry, 35(8), 1129-1142. https://doi.org/10.1016/s0038-0717(03)00165-2

Kappenberg, A., Bläsing, M., Lehndorff, E., \& Amelung, W. (2016). Black carbon assessment using benzene polycarboxylic acids: Limitations for organic-rich matrices. Organic Geochemistry, 94, 47-51. https://doi.org/10.1016/j.orggeochem.2016.01.009

Keil, R. G., \& Kirchman, D. L. (1994). Abiotic transformation of labile protein to refractory protein in sea water. Marine Chemistry, 45, 187-196. https://doi.org/10.1016/0304-4203(94)90002-7

Khodadad, C. L. M., Zimmerman, A. R., Green, S. J., Uthandi, S., \& Foster, J. S. (2011). Taxa-specific changes in soil microbial community composition induced by pyrogenic carbon amendments. Soil Biology and Biochemistry, 43, 385-392. https://doi.org/10.1016/j. soilbio.2010.11.005

Kieber, D. J., McDaniel, J., \& Mopper, K. (1989). Photochemical source of biological substrates in sea water: Implications for carbon cycling. Nature, 341, 637-639. https://doi.org/10.1038/341637a0

Kiikkila, O., Smolander, A., \& Kitunen, V. (2013). Degradability, molecular weight and adsorption properties of dissolved organic carbon and nitrogen leached from different types of decomposing litter. Plant and Soil, 373(1-2), 787-798. https://doi.org/10.1007/ s11104-013-1837-3

Kim, S., Kaplan, L. A., \& Hatcher, P. G. (2006). Biodegradable dissolved organic matter in a temperate and a tropical stream determined from ultra-high resolution mass spectrometry. Limnology \& Oceanography, 51(2), 1054-1063. https://doi.org/10.4319/lo.2006.51.2.1054

Kolb, S., \& Stacheter, A. (2013). Prerequisites for amplicon pyrosequencing of microbial methanol utilizers in the environment. Frontiers in Microbiology, 4, 268. https://doi.org/10.3389/fmicb.2013.00268

Lee, Y., Lee, B., Hur, J., Min, J.-O., Ha, S.-Y., Ra, K., et al. (2016). Biodegradability of algal-derived organic matter in a large artificial lake by using stable isotope tracers. Environmental Science \& Pollution Research, 23(9), 8358-8366. https://doi.org/10.1007/s11356-016-6046-1

Lin, Y., Karlen, S. D., Ralph, J., \& King, J. Y. (2018). Short-term facilitation of microbial litter decomposition by ultraviolet radiation. The Science of the Total Environment, 615, 838-848. https://doi.org/10.1016/j.scitotenv.2017.09.239

Lindell, M. J., Granéli, W., \& Tranvik, L. J. (1995). Enhanced bacterial growth in response to photochemical transformation of dissolved organic matter. Limnology \& Oceanography, 40, 195-199. https://doi.org/10.4319/lo.1995.40.1.0195

Mann, P. J., Sobczak, W. V., Larue, M. M., Bulygina, E., Davydova, A., Vonk, J. E., et al. (2014). Evidence for key enzymatic controls on metabolism of Arctic river organic matter. Global Change Biology, 20(4), 1089-1100. https://doi.org/10.1111/gcb.12416

Marschner, B., \& Kalbitz, K. (2003). Controls of bioavailability and biodegradability of dissolved organic matter in soils. Geoderma, 113(3), 211-235. https://doi.org/10.1016/s0016-7061(02)00362-2

McGinnis, G. D., Boraazjani, H., McFarland, L. K., \& Strobel, D. A. (1988). Characterisation and laboratory testing soil treatability studies for creosote and pentachlorophenol sludges and contaminated soil (USEPA, Report No. 60/2-88/055). Retrieved from https://nepis.epa. gov/Exe/ZyPURL.cgi?Dockey=20012OKA.TXT

Miller, W. L., \& Moran, M. A. (1997). Interaction of photochemical and microbial processes in the degradation of refractory dissolved organic matter from a coastal marine environment. Limnology \& Oceanography, 42(6), 1317-1324. https://doi.org/10.4319/lo.1997.42.6.1317

Moran, M. A., \& Zepp, R. G. (1997). Role of photoreactions in the formation of biologically labile compounds from dissolved organic matter. Limnology \& Oceanography, 42(6), 1307-1316. https://doi.org/10.4319/lo.1997.42.6.1307

Mukherjee, A., \& Zimmerman, A. R. (2013). Organic carbon and nutrient release from a range of laboratory-produced biochars and biochar-soil mixtures. Geoderma, 193-194, 122-130. https://doi.org/10.1016/j.geoderma.2012.10.002

Myers-Pigg, A. N., Louchouarn, P., Amon, R. M. W., Prokushkin, A., Pierce, K., \& Rubtsov, A. (2015). Labile pyrogenic dissolved organic carbon in major Siberian Arctic rivers: Implications for wildfire-stream metabolic linkages. Geophysical Research Letters, 42, 377-385. https://doi.org/10.1002/2014gl062762

Nierop, K., Preston, C., \& Verstraten, J. (2006). Linking the B ring hydroxylation pattern of condensed tannins to C, N and P mineralization. A case study using four tannins. Soil Biology and Biochemistry, 38(9), 2794-2802. https://doi.org/10.1016/j.soilbio.2006.04.049

Norwood, M. J., Louchouarn, P., Kuo, L.-J., \& Harvey, O. R. (2013). Characterization and biodegradation of water-soluble biomarkers and organic carbon extracted from low temperature chars. Organic Geochemistry, 56, 111-119. https://doi.org/10.1016/j. orggeochem.2012.12.008

Payne, C. M., Knott, B. C., Mayes, H., Hansson, H., Himmel, M. E., Sandgren, M., et al. (2015). Fungal cellulases. Chemical Reviews, 115(3), 1208-1448. https://doi.org/10.1021/cr500351c

Qualls, R. G. (2005). Biodegradability of fractions of dissolved organic carbon leached from decomposing leaf litter. Environmental Science \& Technology, 39(6), 1616-1622. https://doi.org/10.1021/es049090o

Qualls, R. G., \& Haines, B. L. (1992). Biodegradability of dissolved organic matter in forest throughfall, soil solution, and stream water. Soil Science Society of America Journal, 56(2), 578-586. https://doi.org/10.2136/sssaj1992.03615995005600020038x 
Roebuck, J. A., Podgorksi, D. C., Wagner, S., \& Jaffe, R. (2017). Photodissolution of charcoal and fire-impacted soil as a potential source of dissolved black carbon in aquatic environments. Organic Geochemistry, 112, 16-21. http://10.1016/j.orggeochem.2017.06.018

Rossel, P. E., Vähätalo, A. V., Witt, M., \& Dittmar, T. (2013). Molecular composition of dissolved organic matter from a wetland plant (Juncus effusus) after photochemical and microbial decomposition (1.25 yr): Common features with deep sea dissolved organic matter. Organic Geochemistry, 60, 62-71. https://doi.org/10.1016/j.orggeochem.2013.04.013

Sack, U., Hofrichter, M., \& Fritsche, W. (1997). Degradation of polycyclic aromatic hydrocarbons by manganese peroxidase of Nematoloma frowardii. FEMS Microbiology Letters, 152, 227-234. https://doi.org/10.1111/j.1574-6968.1997.tb10432.x

Santos, F., Wagner, S., Rothstein, D., Jaffe, R., \& Miesel, J. R. (2017). Impact of a historical fire event on pyrogenic carbon stocks and dissolved pyrogenic carbon in spodosols in Northern Michigan. Frontiers in Earth Science, 5. https://doi.org/10.3389/feart.2017.00080

Santos, F., Wymore, A. S., Jackson, B. K., Sullivan, S. M. P., McDowell, W. H., \& Berne, A. A. (2019). Fire severity, time since fire, and siteeve characteristics influence streamwater chemistry at baseflow conditions in catchments of the Sierra Nevada, California, USA. Fire Ecology, 15. https://doi.org/10.1186/s42408-018-0022-8

Schwesig, D., Kalbitz, K., \& Matzner, E. (2003). Mineralization of dissolved organic carbon in mineral soil solution of two forest soils. Journal of Plant Nutrition and Soil Science, 166(5), 585-593. https://doi.org/10.1002/jpln.200321103

Sergides, C. A., Jassim, J. A., Chughtai, A. R., \& Smith, D. M. (1987). The structure of hexane soot. Part III: Ozonation studies. Applied Spectroscopy, 41, 482-492. https://doi.org/10.1366/0003702874448805. Retrieved from https://www.osapublishing.org/as/abstract. cfm?uri=as-41-3-482

Sims, R. C., Doucette, W. J., McLean, J. E., Grenney, W. J., \& Dupont, R. R. (1988). Treatment potential for 56 EPA listed hazardous chemicals in soil (USEPA, Report No. 600/6-88/001). Retrieved from https://cfpub.epa.gov/si/si_public_record_Report. $\mathrm{cfm} ? \mathrm{Lab}=\mathrm{ORD} \&$ dirEntryID $=46060$

Sorrenti, G., Masiello, C. A., Dugan, B., \& Toselli, M. (2016). Biochar physico-chemical properties as affected by environmental exposure. The Science of the Total Environment, 563-564, 237-246. https://doi.org/10.1016/j.scitotenv.2016.03.245

Spencer, R. G. M., Mann, P. J., Dittmar, T., Eglinton, T. I., McIntyre, C., Holmes, R. M., et al. (2015). Detecting the signature of permafrost thaw in Arctic rivers. Geophysical Research Letters, 42, 2830-2835. https://doi.org/10.1002/2015gl063498

Spencer, R. G. M., Stubbins, A., Hernes, P. J., Baker, A., Mopper, K., Aufdenkampe, A. K., et al. (2009). Photochemical degradation of dissolved organic matter and dissolved lignin phenols from the Congo River. Journal of Geophysical Research, 114, 1-12. https://doi. org/10.1029/2009jg000968

Strauss, E. A., \& Lamberti, G. A. (2002). Effect of dissolved organic carbon quality on microbial decomposition and nitrification rates in stream sediments. Freshwater Biology, 47(1), 65-74. https://doi.org/10.1046/j.1365-2427.2002.00776.x

Stubbins, A., Hood, E., Raymond, P. A., Aiken, G. R., Sleighter, R. L., Hernes, P. J., et al. (2012). Anthropogenic aerosols as a source of ancient dissolved organic matter in glaciers. Nature Geoscience, 5(3), 198-201. https://doi.org/10.1038/ngeo1403

Stubbins, A., Niggemann, J., \& Dittmar, T. (2012). Photo-lability of deep ocean dissolved black carbon. Biogeosciences, 9(5), 1661-1670. https://doi.org/10.5194/bg-9-1661-2012

Tejirian, A., \& Xu, F. (2011). Inhibition of enzymatic cellulolysis by phenolic compounds. Enzyme and Microbial Technology, 48, $239-247$. https://doi.org/10.1016/j.enzmictec.2010.11.004

Tian, J.-H., P. A. M., Gelhaye, A.-M. E., \& Peu, P. (2014). Occurrence of lignin degradation genotypes and phenotypes among prokaryotes. Applied Microbiology and Biotechnology, 98, 9527-9544. https://doi.org/10.1007/s00253-014-6142-4

Tranvik, L., \& Kokalj, S. (1998). Decreased biodegradability of algal DOC due to interactive effects of UV radiation and humic matter. Aquatic Microbial Ecology, 14, 301-307. https://doi.org/10.3354/ame014301

van Hees, P. A. W., Jones, D. L., Finlay, R., Godbold, D. L., \& Lundström, U. S. (2005). The carbon we do not see-the impact of low molecular weight compounds on carbon dynamics and respiration in forest soils: A review. Soil Biology and Biochemistry, 37(1), 1-13. https://doi. org/10.1016/j.soilbio.2004.06.010

Vujinović, T., Clough, T. J., Curtin, D., Meenken, E. D., Lehto, N. J., \& Beare, M. H. (2019). Quantity and biodegradability of dissolved organic matter released from sequentially leached soils, as influenced by the extent of soil drying prior to rewetting. Soil Research, 57(4), 374-386. http://doi.org/10.1071/SR18172

Waggoner, D. C., Chen, H., Willoughby, A. S., \& Hatcher, P. G. (2015). Formation of black carbon-like and alicyclic aliphatic compounds by hydroxyl radical initiated degradation of lignin. Organic Geochemistry, 82, 69-76. https://doi.org/10.1016/j.orggeochem.2015.02.007

Wagner, S., Brandes, J., Spencer, R. G. M., Ma, K., Rosengard, S. Z., Moura, J. M. S., \& Stubbins, A. (2019). Isotopic composition of oceanic dissolved black carbon reveals non-riverine source. Nature Communications, 10, 5064. https://doi.org/10.1038/s41467-019-13111-7

Wagner, S., Cawley, K. M., Rosario-Ortiz, F. L., \& Jaffé, R. (2015). In-stream sources and links between particulate and dissolved black carbon following a wildfire. Biogeochemistry, 124, 145-161. https://doi.org/10.1007/s10533-015-0088-1

Wagner, S., Jaffé, R., \& Stubbins, A. (2018). Dissolved black carbon in aquatic ecosystems. Limnology \& Oceanography, 3, 168-185. https:// doi.org/10.1002/lol2.10076

Ward, C. P., Nalven, S. G., Crump, B. C., Kling, G., \& Cory, R. (2017). Photochemical alteration of organic carbon draining permafrost soils shifts microbial metabolic pathways and stimulates respiration. Nature Communications, 8, 1-8. https://doi.org/10.1038/ s41467-017-00759-2

Ward, C. P., Sleighter, R. L., Hatcher, P. G., \& Cory, R. M. (2014). Insights into the complete and partial photooxidation of black carbon in surface waters. Environmental Sciences: Processes Impacts, 16(4), 721-731. https://doi.org/10.1039/c3em00597f

Wetzel, R. G., Hatcher, P. G., \& Bianchi, T. S. (1995). Natural photolysis by ultraviolet irradiance of recalcitrant dissolved organic matter to simple substrates for rapidbacterial metabolism. Limnology \& Oceanography, 40(8), 1369-1380. https://doi.org/10.4319/ lo.1995.40.8.1369

Whitty, S. D., Waggoner, D. C., Cory, R. M., Kaplan, L. A., \& Hatcher, P. G. (2019). Direct noninvasive ${ }^{1}$ H NMR analysis of stream water DOM: Insights into the effects of lyophilization compared with whole water. Magnetic Resonance in Chemistry, 1-14. https://doi. $\operatorname{org} / 10.1002 / \mathrm{mrc} .4935$

Wolter, M., Zadrazil, F., Martens, R., \& Bahadir, M. (1997). Degradation of eight highly condensed polycyclic aromatic hydrocarbons by Pleurotus sp. Florida in solid wheat straw substrate. Applied Microbiology and Biotechnology, 48, 398-404. https://doi.org/10.1007/ s002530051070

Wozniak, A. S., Goranov, A. I., Mitra, S., Bostick, K. W., Zimmerman, A. R., Schlesinger, D. R., et al. (2020). Molecular heterogeneity in pyrogenic dissolved organic matter from a thermal series of oak and grass chars. Organic Geochemistry, 148, 104065 https://doi.org/10.1016/j.orggeochem.2020.104065 
Wozniak, A. S., Shelley, R. U., Sleighter, R. L., Abdulla, H. A. N., Morton, P. L., Landing, W. M., et al. (2013). Relationships among aerosol water soluble organic matter, iron and aluminum in European, North African, and Marine air masses from the 2010 US GEOTRACES cruise. Marine Chemistry, 154, 24-33. https://doi.org/10.1016/j.marchem.2013.04.011

Zimmerman, A. R. (2010). Abiotic and microbial oxidation of laboratory-produced black carbon (biochar). Environmental Science \& Technology, 44, 1295-1301. https://doi.org/10.1021/es903140c

Zimmerman, A. R., Gao, B., \& Ahn, M.-Y. (2011). Positive and negative carbon mineralization priming effects among a variety of biochar-amended soils. Soil Biology and Biochemistry, 43, 1169-1179. https://doi.org/10.1016/j.soilbio.2011.02.005

Zimmerman, A. R., \& Ouyang, L. (2019). Priming of pyrogenic C (biochar) mineralization by dissolved organic matter and vice versa. Soil Biology and Biochemistry, 130, 105-112. https://doi.org/10.1016/j.soilbio.2018.12.011

Ziolkowski, L. A., Chamberlin, A. R., Greaves, J., \& Druffel, E. R. M. (2011). Quantification of black carbon in marine systems using the benzene polycarboxylic acid method: A mechanistic and yield study. Limnology and Oceanography: Methods, 9, 140. https://doi org/10.4319/lom.2011.9.140

Ziolkowski, L. A., \& Druffel, E. R. M. (2010). Aged black carbon identified in marine dissolved organic carbon. Geophysical Research Letters, 37, 1-4. https://doi.org/10.1029/2010gl043963 